\title{
7th Advanced Materials Science and Nanotechnology Symposium to be
} held December 2012

T he 7th Advanced Materials Science and Nanotechnology Symposium (SCiMAN7) will be held in Costa Rica on December 10-11, 2012. Organized by the Materials Science and Engineering Research Center and the Materials Science and Engineering Institutional Program, both of the University of Costa Rica at San José, the symposium represents an effort to provide to the local and regional scientific and engineering community a venue to share results obtained from research activities in materials science and engineering as well as nanotechnology, mainly developed locally. Most of the presenters are scientists, engineers, and students from local universities and national laboratories, along with the participation of international invited researchers. The symposium is endorsed by the Materials Research Society.

For more information, contact Arturo Ramírez-Porras, Director of CICIMA, University of Costa Rica, San José, Costa Rica; (506)2511-6573; fax (506)22255511; and email aramirez@fisica.ucr. ac.cr; or access www.cicima.ucr.ac.cr/ simposios.

Advanced materials and nanotechnologies discussed at YUCOMAT 2011 www.mrs-serbia.org.rs

T he Thirteenth Annual YUCOMAT Conference was held in Herceg Novi, Montenegro, September 5-9, 2011. It was organized by the Materials Research Society of Serbia (MRSSerbia), under the auspices of the Federation of European Materials Societies and endorsed by the Materials Research Society. Participants from 34 countries presented their latest research results in various areas including the field of smart mechanochemistry, controlled release of drugs, solutions for key problems of sustainable development, metal extraction, alloying, nanocomposite synthesis, processing of traditional and advanced ceramics, and catalysis.

At the Opening Ceremony, president of MRS-Serbia Dragan Uskokovic said, "Intensive communication between the developing countries and the developed ones is of crucial importance for the progress of both. For affluent social islands surrounded by all but prosperous milieus have been over and over again shown as unsustainable. To ensure the thriving of the developed world, there-

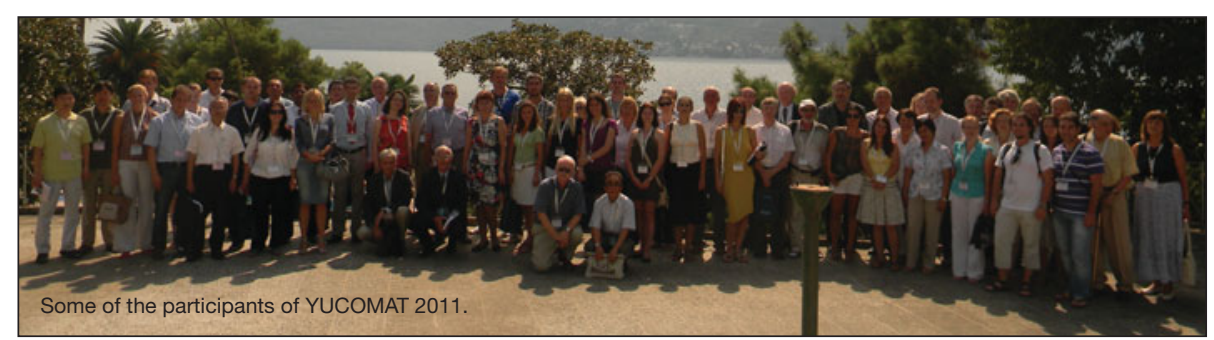

fore, its eyes should be kept on assisting the small ones in their progress. On the other hand, some of the most remarkable scientific discoveries are known to have stemmed from miniscule funding, as pointed out these days by historians of science. Modest research environments, such as those existing in many small countries, are thus often thought to be fertile grounds for the invention of simple and yet extraordinarily efficient and eco-friendly methods and approaches."

At YUCOMAT 2011 more than 200 participants from around the world gathered to hear 23 lectures given by invited speakers in four plenary sessions, 45 papers presented in five oral sessions, and 120 papers presented in three poster sessions, within five one-day symposia dedicated to advanced methods in materials synthesis and processing, advanced materials for high-technology applications, nanostructured materials, composites, and biomaterials. The conference included an exhibition of innovative scientific equipment.

YUCOMAT 2011 Programme and the Book of Abstracts is available to view at www.mrs-serbia.org.rs/images/ YUCOMAT2011-web.pdf.

The next YUCOMAT Conference will also be held in Herceg Novi on September 3-7, 2012.

Dragan Uskokovic President of MRS-Serbia

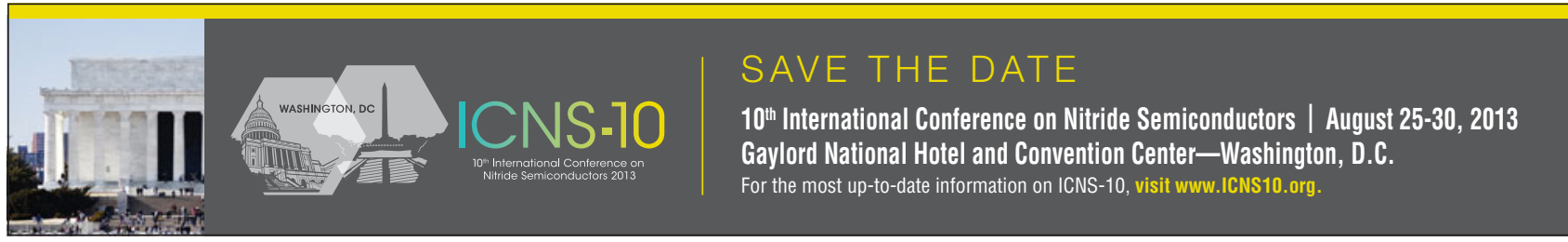

